\title{
The Effect of Online Review about Company on Organizational Attraction and Application Intention
}

\author{
Xinren Bao ${ }^{1, a}$, Mengqi Wang ${ }^{1, b}$ and Liying Ding ${ }^{2, c}$ \\ ${ }^{1}$ School of Management, Donghua University, Shanghai, 200051, China \\ ${ }^{2}$ School of Foreign Languages, Donghua University, Shanghai, 200051, China
}

Keywords: Online review; Job seekers; Organizational attraction; Application intention; Internet

\begin{abstract}
Online review from social networks has been an influential resource of information for job seekers to know more about companies they interested. This leads us to suppose that online review about companies may influence organizational attractiveness to job seekers and their initial decisions. To confirm our hypotheses, we conducted a study based on 127 responses to a questionnaire especially designed to examine. The results indicate that online review is positively related to organizational attraction to job candidates and ultimately influencing their application intention. The previous study of factors influencing job seeker's initial decision and organizational attraction focused on the perspective of company, such as company's brand or image, features of organizational website. Little is from the electronic word-of-mouth perspective. This paper is just to fill the vacancy area and make a further validation about the importance of electronic word of mouth for company. Moreover, few suggestions are given to companies and job seekers for reference.
\end{abstract}

\section{Introduction}

Decisions of applicants to apply to organization obviously influence quality and quantity of potential candidates (Collins \& Han, 2004) [1], which relates to recruitment performance of organizations and finally impact their stability and development.as a result of this, more attention should be pay to key factors that influence application intention. limited research attention still found proof to demonstrate the effect of information non-company directly provided such as media and peer word of mouth on applicants' attitudes and behaviors (Collins \& Stevens, 2002) [2], and different from information from company normal channels, non-company sources can help applicants to have a more accurate perception about target company due to the fact that their positions are not exactly same with companies. Especially, negative information from media or peer might make applicants lose interest in companies (Cable \& Turban, 2001) [3], which means the degree online review influences applicants' decision cannot be underestimated in today, However, currently we have little understanding of the extent to which online review influences job seekers and how it impacts. That is what we want to explore in this paper.

\section{Theory and Hypotheses}

With the popularity of smartphone, it's more convenient for people to make online reviews about products and services and its amazing spread in depth and breadth even changed our lifestyle. Most people shared their experience and feelings about companies they work or had worked for on social websites or virtual communities for the purpose of emotion express or helping others, The experience mainly involve chances for career development, work environment, company's prospect as well as work stress and others which are rightly we job seekers especially new graduates cared about, this obviously brought companies new challenges and received scholars' high attention. Lin H F (2015) [4] has found that informational social influence has a strong effect on job seeker attraction and application decisions. According to above analysis, we can suppose that,

H1: online review about company has a significant positive effect on application intention.

Larsen and Phillips (2002) [5] extended the application of ELM (Elaboration Likelihood Model) to applicant attraction research. They proposed that throughout the selection process, particularly 
during the initial stages, job applicants are more likely to engage in peripheral processing rather than central processing due to their limited ability and minimal contact with company. Based on information they find from sources target company provided, together with reviews come from peers who have more contact with target company (E.G interviewees, employees) they can make better evaluation about organizational attractiveness. Therefore we posited the following:

$\mathrm{H} 2$ : Online review about company has strong impact on organizational attraction.

Rynes (1991) [6] demonstrated that, given the small amount of information in early job choice process, job seekers' application decisions heavily depends on whether organizations have enough attraction . The $\mathrm{H} 3$ was introduced:

H3: organizational attraction has a strong positive effect on application intention.

From three hypotheses discussed above we can provide our last hypothesis $\mathrm{H} 4$ :

H4: organizational attraction mediated the relationship between online review about company and application intention.

We made a research model depends on above three hypotheses for explicitly presenting relationships among three variables and text these by next empirical study. (Fig. 1)

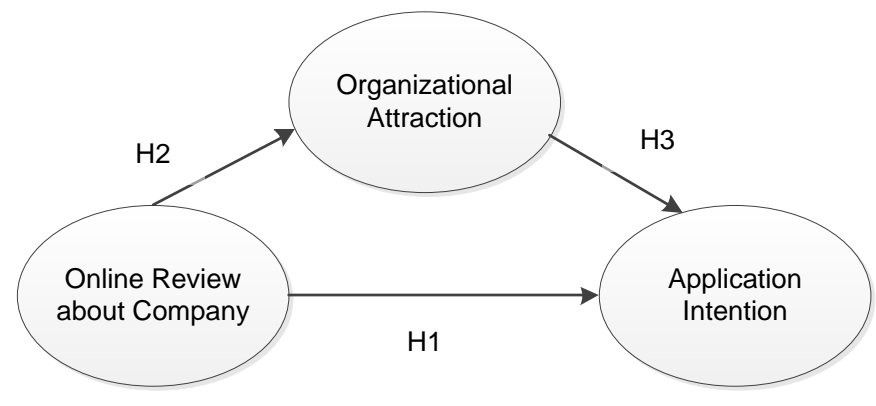

Figure 1. Research Model

\section{Methodology}

Participants. One hundred and twenty-seven effective questionnaires were collected from internet. The sample consisted of $46.5 \%$ male $(\mathrm{N}=59)$ and $53.5 \%$ female $(\mathrm{N}=68)$, their age focuses on the interval of 20-26 years old and the minimum education level among 119 of all participants was bachelor degree. New graduates accounted for $59.1 \%$, $48 \%$ were employed and only $3 \%$ were unemployed.

Measurement. We used six items to assess the online review about company, these items were concluded from previous similar studies (Bambauer - Sachse and Mangold, 2011) [7]. All items were translated into simplified Chinese and measured on a five-point Likert scale ranging from 1(strongly disagree) to 5(strongly agree). An example is, "I often search other job seekers' online review about my target company to know some information that I can't obtain from company resource." The Cronbach's $\alpha$ of this measure was 0.788 in current study.

Five items which have received most attention from previous studies on attraction to organization (Scott Highhouse, FilipLievens \& Even F. Sinar, 2003)[8] were used in this study to measure organizational attraction. The example is "For me, this company would be a good place to work." Similarly, a five-point scale (1=extremely disagree, $5=$ extremely agree) was applied to our measure. The Cronbach's $\alpha$ of this measure was 0.825 in current study.

Five items originated from Bansal \& Voyer (2000) [9] were organized to measure application intention, example is "online reviews influenced my opinions about the company." The response options ranged from 1 to 5 (1=extremely disagree, $5=$ extremely agree). The Cronbach's $\alpha$ of the concept was 0.755 . 


\section{Result}

In order to study the causal relationships among the three variables, and confirm the mediation effect of organizational attraction on relationship between online review among job seeker and application intention, we used the Process macro for SPSS 17(model4; Hayes, 2013)[10], which tests for mediation by calculating confidence intervals using bootstrapping (5000 bootstrapped samples in this analysis). Within the model, online review among job seekers was introduced as independent variable $(\mathrm{X})$, organizational attraction as mediator (M) and application intention as dependent variable (Y).

Table 1 Regression analysis

\begin{tabular}{lllcl}
\hline \hline Independent & Dependent & & \\
Variable & Variable & coeff & $\mathrm{t}$ & $\mathrm{p}$ \\
\hline $\mathrm{X}$ & $\mathrm{M}$ & .34 & 4.1 & 0.0 \\
$\mathrm{X}$ & $\mathrm{Y}$ & .54 & 7.2 & 0.0 \\
$\mathrm{M}$ & $\mathrm{Y}$ & .50 & 6.5 & 0.0 \\
\hline \hline
\end{tabular}

Table 1 presents the results of tests of significance of causal relationship among three variables. Three causal relationships are significant, online review among job seekers has significant positive effect on organizational attraction $(\beta=0.54, \mathrm{t}=7.2, \mathrm{p}=0.0)$, which means that $\mathrm{H} 1 \mathrm{was}$ received. And online review among job seekers also has a strong positive effect on application intention $(\beta=0.34$, $\mathrm{t}=4.1, \mathrm{p}=0.0), \mathrm{H} 2$ can be accepted. Finally, organizational attraction significantly influenced application intention $(\beta=0.5, \mathrm{t}=6.5, \mathrm{p}=0.0)$. $\mathrm{H} 3$ has been demonstrated.

Table 2 Online review about company mediation analysis

\begin{tabular}{|c|c|c|c|c|c|}
\hline \multicolumn{6}{|c|}{ Total effect of $\mathrm{X}$ on $\mathrm{Y}$} \\
\hline Effect & $\mathrm{SE}$ & $\mathrm{t}$ & $p$ & LLCI & ULCI \\
\hline .5 & .1 & 7.2 & .0 & .4 & .6 \\
\hline \multicolumn{6}{|c|}{ Direct effect of $\mathrm{X}$ on $\mathrm{Y}$} \\
\hline Effect & $\mathrm{SE}$ & $\mathrm{t}$ & $\mathrm{p}$ & LLCI & ULCI \\
\hline .4 & .1 & 5.7 & .0 & .3 & .5 \\
\hline \multicolumn{6}{|c|}{ Indirect effect of $\mathrm{X}$ on $\mathrm{Y}$} \\
\hline & & & & BootLLCI & BootULCI \\
\hline & & & & .1 & .2 \\
\hline \multicolumn{6}{|c|}{ Normal theory tests for indirect effect } \\
\hline & & & & $\mathrm{Z}$ & $\mathrm{p}$ \\
\hline & & & & 3.1 & .0 \\
\hline
\end{tabular}

Table 2 shows that as predicted, online review among job seekers $(\mathrm{X})$ has significant direct effect on application intention $(\mathrm{Y})(\mathrm{b}=0.4$, se $=0.1,95 \% \mathrm{CI}=[0.3,0.5])$ and there is significant indirect effect of online review among job seekers on application intention through organizational attraction. because this indirect effect is statistically different from zero, as revealed by a $95 \%$ BC bootstrap confidence interval that is entirely above zero $(\mathrm{CI}=[0.1,0.2])$.the normal theory-based Sobel test $(\mathrm{Z}=3.1, \mathrm{p}<0.001)$ agrees with the inference made using a bias-corrected bootstrap confidence interval[10]. The result showed that mediation effect $(0.1)$ accounted for $20 \%$ of total effect, which means organizational attraction partly mediated the relationship between online review among job seekers and application intention, $\mathrm{H} 4$ was received.

\section{Conclusion}

Wild spread of online reviews among job seekers and its significant influence on applicant's initial 
decisions make us realize that electronic word-of-mouth can be a strong force all companies should pay more attention to. Some important implications in line with our results can be given for reference. From the side of companies, more efforts than before should be put in the operation of official accounts (like Wechat and Micro blogger in China) for positive guidance of job seekers in case that they are misled by some negative subjective online reviews and in turn have inaccurate evaluation about organizational attraction, which finally influence their intention to apply; high reliability in recruitment advertisement can be kept for huge gap in mental from exaggeration leading bad impression. Most importantly, it's imperative for all companies to improve satisfaction of major employees. Employees with high satisfaction will be volunteers to maintain the reputation of companies. From the side of job seekers, they need to learn to distinguish truth from vast quantities of online reviews instead of blindly believing what others said on internet and make good use of accessibility of information for wise decision.

Although we have demonstrated that effect of online review about company on organizational attraction and application intention, whether online review of different features (e.g. Amount of the negative and the positive, judgment ability of receiver, reliability of sender) has effect on application intention in different degree and if has, how they influence? These need our further explore and research.

\section{References}

[1] Collins C J, Han J. Exploring Applicant Pool Quantity and Quality: The Effects of Early Recruitment Practice Strategies, Corporate Advertising, and Firm Reputation, J. Personnel Psychology, 2004, 57(3):685-717.

[2] Collins C J, Cynthia Kay S. The relationship between early recruitment-related activities and the application decisions of new labor-market entrants: a brand equity approach to recruitment, J. Journal of Applied Psychology, 2003, 87(6):1121-33.

[3] Cable D M, Turban D B. Establishing the dimensions, sources and value of job seekers' employer knowledge during recruitment, J. Research in Personnel \& Human Resources Management, 2001, 20(01):115-163.

[4] Lin H F. The impact of company-dependent and company-independent information sources on organizational attractiveness perceptions, J. Journal of Management Development, 2015, 34(8):941-959.

[5] Larsen D A, Phillips J I. Effect of Recruiter on Attraction to the Firm: Implications of the Elaboration Likelihood Model, J. Journal of Business \& Psychology, 2002, 16(3):347-364.

[6] Rynes, S. L. 1991. Recruitment, job choice, and post-hire consequences: A call for new research directions. In M.D.Dunnette and L.M. Hough (Eds.). Handbook of industrial and organizational psychology, Vol. 2(2d ed.): 399-444. Palo Alto, CA: Consulting Psychologists.

[7] Bambauer-Sachse S, Mangold S. Brand equity dilution through negative online word-of-mouth communication, J. Journal of Retailing \& Consumer Services, 2011, 18(1):38-45.

[8] Highhouse S, Lievens F and Sinar E F. Measuring Attraction to Organizations, J. Educational \&Psychological Measurement, 2003, 63(6):986-1001.

[9] Bansal, H. S., Voyer, P. A. (2000). Word-of-mouth processes within a services purchase decision context, J. Journal of Service Research, 3(2), 166-177.

[10] Hayes, A.F. 2013. Introduction to Mediation, Moderation, and Conditional Process Analysis; A Regression-Based Approach, America, Guilford Press .pp.1-54. 